\title{
Sustainable Pneumatic Transport Systems of Cereals
}

\author{
${ }^{1, a}$ Mariana Panaitescu, ${ }^{1, b}$ Gabriela Simona Dumitrescu, ${ }^{1, \mathrm{c}}$ Andrei Alexandru Scupi \\ ${ }^{1}$ Department of Engineering Sciences in Mechanical and Environmental Field \\ Constanta Maritime University \\ Constanta, Romania \\ amarianapan@yahoo.com, ${ }^{b m o n a 22 f e b r u a r i e @ y a h o o . c o m ~ c a n d r e i . s c u p i @ g m a i l . c o m ~}$
}

Received: January 22, 2021 Revised: February 18, 2021. Accepted: March 8, 2021. Published: March 24, 2021.

\begin{abstract}
Technological pneumatic transport installations are designed to move materials from one place to another in various phases of the production process. For example: loadingunloading materials (cereals) using rail and marine transport, air tunnel container transport, supplying combustion installations with burning coal dust. The main parameter in pneumatic transport installations is the velocity of air. For the regime of motion with material particles in suspension, for a given flow material, the higher the velocity is the greater the pressure loss will be and thus the energy consumption for transportation will increase. In horizontal pipes at the beginning of motion flow we have a compact regime, and then due to decrease air velocity a continuous layer regime is forming. This is the apparent motion in wich the pressure losses increase with the decrease of velocity. By reducing the air velocity the thickness of the deposited material increases and the real air passage section decreases and therefore the real air velocity increases, which explains the increase in pressure loss. In vertical pipes if the air velocity decreases below the lower limit of volant transport, after a critical area of instability, a transportation fluidized bed is established, the pressure losses being much larger than the particles in suspension mode. If the velocity further decreases the particles can not be entrained in the air.
\end{abstract}

Keywords-transport, pneumatic, sustainable, installations, cereal, aspiration, silo, cyclone, pipeline.

\section{INTRODUCTION}

In pneumatic transport installations [1] the air circulation is done in order to transport solid materials under dynamic pressure effect of the air flow in pipes. Transportation of materials can be mechanically (conveyors, bucket, etc.), through pneumatic pipelines using air as the carrier or combined mechanical and pneumatic. The units consist of two parts: a device for picking up the material (along with the air) in a transportation network and a retaining device (separation) of the material transported.

The material must fulfill a number of requirements to be transported in good condition: to present a size composition and a density for which the transport and the separation should be economical, not to adhere to the surface of the pipes, not to degrade by crushing during transport, the required temperature for transport should not affect the resistance of pipes and of the equipment used, not to emit explosive or corrosive vapors, do not change their chemical properties during transport. Pneumatic transport is based on the principle of entraining solid material particle by a current of air or other gas moving with a certain velocity through a pipe. With this type of installations we can transport solid tiny elements: wheat, corn, oats, barley, ash, clay, cement, wood chips, sawdust, cellulose.

Moving of material is made on a horizontal plane over a distance of $350 \mathrm{~m} \div 400 \mathrm{~m}$ or on a vertical plane over a distance of $45 \mathrm{~m}$.

\section{PNEUMATIC TRANSPORT SYSTEMS}

Building a pneumatic transport system and its requirea equipment along with economic indicators vary from one units to another depending on system pressure.

From the pressure point of view we can distinguish:

- systems with discharge - low, medium or high pressure;

- systems with aspiration (fig. 1.1);

- combined systems (mixt) - open or closed systems.

In pneumatic transport systems by aspiration (Fig. 1), the material is transported with the help of a exhauster mounted at the end of pneumatic unit end so that it lies entirely on air depression. The exhauster produces a depression of $0,5 \div 0,6$ bar necessary for transport of material. Granular material with is sucked along with the air through the suction head and transported to the silo discharge pipe. Separation of grain last air is entrained in a cyclone. Adjusting depression is by nature, grain size and friction losses that occur along the entire length of the installation. Pneumatic conveying aspiration is effective in downloading materials from cars, platforms, trailers etc. At distances up to $120 \mathrm{~m}$,

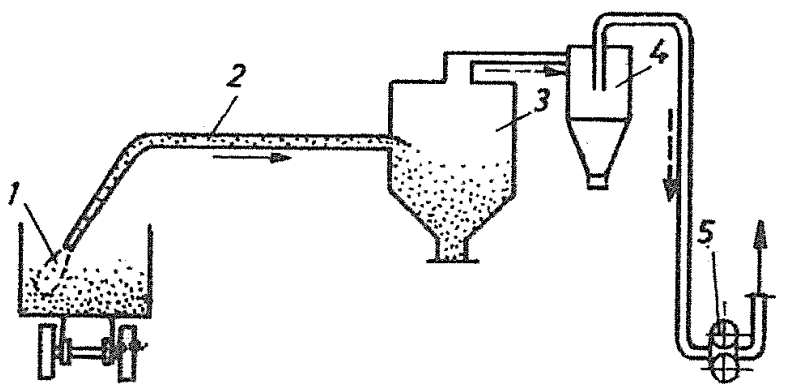

Figure 1 Pneumatic transport system with suction [1] 1 - suction head, 2 - Condor transport 3 - Silo, 4 - cyclone, 5 exhaustive.

\section{MATHEMATICAL MODELING OF THE PROCESS}

\section{A. The speed of material in air transport pipes}

In the pipeline the material transported behaves differently from air, especially due to its higher mass. The forces exerted 
on the particle (e.g. friction with the pipe walls, the impact of particles one with another, its spin, weight, drag, etc.) produce acceleration or slowing down of the material, so that to maintain the required speed transport its necessary an additional energy consumption.

a) operating speed of the material - is the speed limit that the particles in dynamic equilibrium have. The relationships are calculated for a rarefied flow (volant transport).

For relative speeds: $v_{r}=v_{a}-v_{m}$ and a $R e>2 \cdot 10^{5}$, the relation is :

$$
\frac{v_{m}}{v_{a}}=\frac{1-\left[\frac{\lambda^{*} F r^{*}}{2}\left(1-\frac{\beta F r^{*}}{F r}\right)+\frac{\beta F r^{*}}{F r}\right]^{0,5}}{1-\frac{\lambda^{*} F r^{*}}{2}}
$$

For high speed transmission, when considered $\beta=0$, the relation becomes:

$$
\frac{v_{m}}{v_{a}}=\frac{1}{1-\left(\frac{\lambda^{*} F r^{*}}{2}\right)^{0,5}}
$$

in which:

$\mathrm{v}_{\mathrm{a}}, \mathrm{v}_{\mathrm{m}}-$ velocity of air and material in the pipe $[\mathrm{m} / \mathrm{s}]$;

$\mathrm{v}_{\mathrm{p}}$ - floating velocity of the material $[\mathrm{m} / \mathrm{s}]$;

$1^{*}$ - initial friction coefficient depending on the material transported;

b - coefficient of friction between the moving material particles and pipeline;

$\mathrm{b}=1$ for vertical pipes; $\mathrm{b}=\mathrm{v}_{\mathrm{p}} / \mathrm{v}_{\mathrm{a}}$ for horizontal pipe;

$\mathrm{Fr}-$ Froude criterion, is $\mathrm{Fr}=\mathrm{v}_{\mathrm{a}}{ }^{2} /(\mathrm{gD})$ si Fr* $=\mathrm{v}_{\mathrm{p}}{ }^{2} /(\mathrm{gD})$;

$\mathrm{D}$ - diameter of the pipe [m].

For all types of particles, including for dust, the default relation is recommended:

$$
\left(\frac{\psi^{\prime}}{\psi}\right) \cdot\left(\frac{v_{r}}{v_{p}}\right)^{2}-\left(\frac{v_{m}{ }^{2}}{2 g D}\right) \cdot \lambda^{*}-\beta=0
$$

(3)

where $\psi^{\prime}$ and $\psi$ are the aerodynamic drag coefficients.

b) velocity of the material during acceleration - between time of placing material in pneumatic pipeline and achieve its operating velocity, there is a period of acceleration of the material, which its corresponds a length of acceleration. Upon the particle is acting the ascension ( $\left.F_{A}\right)$ force (fig.2) and the gravity $(\mathrm{G})$ force, the retention force due to collisions between particles (Fi). All of the forces create a resultant which represents the Newtonian acceleration force $\left(F_{a c c}\right)$.

$$
\begin{gathered}
F_{A}=c \cdot S \cdot m \cdot \frac{v_{r}{ }^{2} \rho_{a}}{2} ; \\
G=m \cdot g ; \\
F_{i}=i \cdot m \cdot \frac{v_{m}{ }^{2}}{2} ; F_{a c c}=m \cdot \frac{d v_{m}}{d t}
\end{gathered}
$$

in which:

c - coefficient of drag;

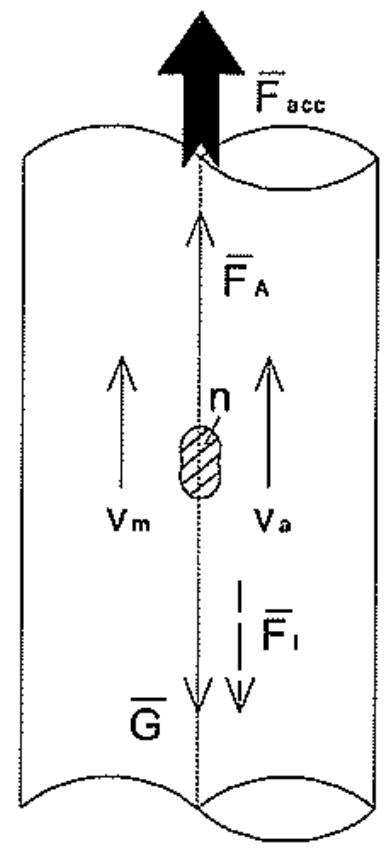

$\mathrm{S}-$ the section of particle $\left[\mathrm{m}^{2}\right]$;

Fig. 2. The action of the forces of acceleration on the particle[1]

$\mathrm{v}_{\mathrm{r}}=\mathrm{v}_{\mathrm{a}}-\mathrm{v}_{\mathrm{m}}$, relative speed $[\mathrm{m} / \mathrm{s}]$;

$\rho_{\mathrm{a}}-$ the air density $\left[\mathrm{kg} / \mathrm{m}^{3}\right]$;

$\mathrm{m}$ - mass of material transported $[\mathrm{kg}]$;

$\mathrm{i}$ - coefficient of impact, depending on the size and nature of the particle.

Vertical projection of forces equilibrium equation is obtained:

$$
\begin{gathered}
F_{a c c}+F_{A}-G-F_{i}=0 \\
m \frac{d v_{m}}{d \tau}+c \cdot S \cdot m \cdot \frac{v_{r}{ }^{2} \rho_{a}}{2} \cdot-m g-i \cdot m \cdot \frac{v_{m}{ }^{2}}{2}=0 \\
m \frac{d v_{m}}{d \tau}=-c \cdot S \cdot m \cdot \frac{\left(v_{a}-v_{m}\right)^{2} \rho_{a}}{2}+m g+i \cdot m \cdot \frac{v_{m}{ }^{2}}{2}
\end{gathered}
$$

If note:

$A=-\frac{c \cdot S}{2} \rho_{a}+\frac{i}{2} ; B=v_{m} v_{a} \cdot c \cdot S \cdot \rho_{a}$

$C=-c \cdot S \cdot \frac{v_{a}^{2}}{2}+g$;

Differential equation can be written as:

$$
\frac{d v_{m}}{d \tau}=A \cdot v_{m}^{2}-B \cdot v_{m}+C
$$

Admitting that $v_{a}$ is constant, we can separate the variables and then integrate them:

$$
m \int_{0}^{v_{m}} \frac{d v_{m}}{A v_{m}^{2}-B v_{m}+C}=\int_{0}^{t} d t
$$

After integration is obtained the following: 
$t=\frac{m}{\sqrt{B^{2}-4 A C}} \cdot \ln \left[\left(\frac{2 A v_{m}-B-\sqrt{B^{2}-4 A C}}{2 A v_{m}-B+\sqrt{B^{2}-4 A C}}\right) K_{0}\right]$

The value of constant $\mathrm{K}_{0}$ is obtained by introducing the initial values: $\mathrm{t}=0 ; \mathrm{v}_{\mathrm{m}}=0$

$$
K_{0}=\frac{B-\sqrt{B^{2}-4 A C}}{B+\sqrt{B^{2}-4 A C}}
$$

Replacing in equation (12) $\mathrm{K}_{0}$ with is formula, we obtain:

$$
t=\frac{m}{\sqrt{B^{2}-4 A P_{0}}} \ln \frac{\left(B-\sqrt{B^{2}-4 A C}\right) v_{m}-2 C}{\left(B+\sqrt{B^{2}-4 A C}\right) v_{m}-2 C}
$$

Equation is solved with the notations:

$$
\varphi=\frac{\sqrt{B^{2}-4 A C}}{m} ; \delta=\frac{B-m \cdot \varphi}{B+m \cdot \varphi}
$$

Material resulting in acceleration speed:

$$
v_{m}=v_{a} \cdot \beta \cdot \frac{1-e^{-\varphi x}}{1-\delta e^{-\varphi x}}
$$

Acceleration time is determined from the relationship generally being an inverse function of velocity:

$$
\tau_{a c c}=\frac{1}{\varphi} \ln \frac{1-\delta \frac{v_{m}}{v_{a} \cdot \beta}}{1-\frac{v_{m}}{v_{a} \cdot \beta}}
$$

The length of the acceleration resulting from the integration of the equation:

$$
l_{a c c}=\int_{0}^{\tau_{a c c}} v_{m} d \tau
$$

Length of straight pipelines for acceleration is determined by the time required for the velocity of material to reach $95 \%$ of the operating velocity. Pressure difference required to accelerate the material is determined by the relationship:

$$
\Delta p=G_{m} \frac{v_{m 2}-v_{m 1}}{0,785 D^{2}}
$$

in which:

$\mathrm{G}_{\mathrm{m}}$-mass flow of material $[\mathrm{kg} / \mathrm{s}]$;

$\mathrm{V}_{\mathrm{m} 1}, \mathrm{~V}_{\mathrm{m} 2}$ - initial velocity, final velocity (after acceleration) of the material $[\mathrm{m} / \mathrm{s}]$;

$\mathrm{D}$ - the diameter of the transport [m].

c) velocity of the material in curved pipelines

In curved pipelines centrifugal force due to air material separation occurs, the particles form a layer lining on the outer wall of the pipeline wall due to friction, the layer of material is slowed down drastically, the velocity decreases but the pressure changes very few percentage loss due to clean air passage. After the curved pipeline the material has to be accelerated on the straight sections of pipeline.

The forces acting on the particle (Fig. 3) are: normal force at the pipe wall $(\mathrm{N})$, the friction force $\left(\mathrm{F}_{\mathrm{f}}\right)$, inertial force $\left(\mathrm{F}_{\mathrm{i}}\right)$ (mass $\mathrm{x}$ acceleration). Forces resulting from the project:

$$
F_{i}=-m \frac{d v}{d \tau} ; F_{f}=\eta \cdot N=\eta \cdot \frac{m v^{2}}{R}
$$

For an element of a length $d s=v d \tau=R d \varphi$, where $R=v \cdot \frac{d v}{d \tau}$. Substituting into the equation and introducing simplification and putting boundary conditions, we obtain:

$$
\int_{v 1}^{v 2} \frac{d v}{v}=-\eta \int_{0}^{\varphi 2} d \varphi ; \ln \frac{v_{2}}{v_{1}}=-\eta \cdot \varphi ; \frac{v_{2}}{v_{1}}=e^{-\eta \varphi}
$$

in which:

$\mathrm{f}$ - curve angle [radian];

$\mathrm{h}$ - the coefficient of friction of the material of the pipe wall, experimentally determined;

$\mathrm{R}-$ radius $[\mathrm{m}]$.

$$
v_{2}=v_{1} \cdot e^{-\eta \varphi}
$$

Note that the velocity at the exit of curve does not depend on the radius of curvature and is even lower with both friction coefficient is higher, which is why these plants are not allowed to curve segments are shown curves enamel or other processing to reduce the coefficient of friction. Velocity $v_{2}$ is even smaller the higher the opening angle of the curve is, which leads to the recommendation on the composition of a set of two curves $45^{\circ}$ which is inserted between a straight section that will foster and return to operating speed compared to a single curve of $90^{\circ}$.

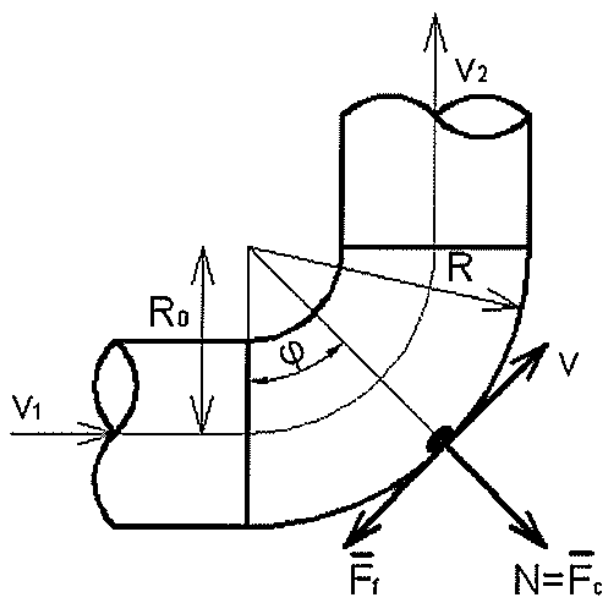

Fig. 3. Particle motion in a horizontal elbow [1] 


\section{NUMERICAL SIMULATION OF THE PROCESS USING FINITE VOLUME METHOD}

For the numerical simulation we have used a numerical software Ansys-Fluent v.13.0. This program is based on the finite volume method.

The geometry created is similar to Fig. 3 and has the following dimensions (Fig. 4):

- the pipelines arms length $=3 \mathrm{~m}$;

- the pipelines diameter $=0.6 \mathrm{~m}$.

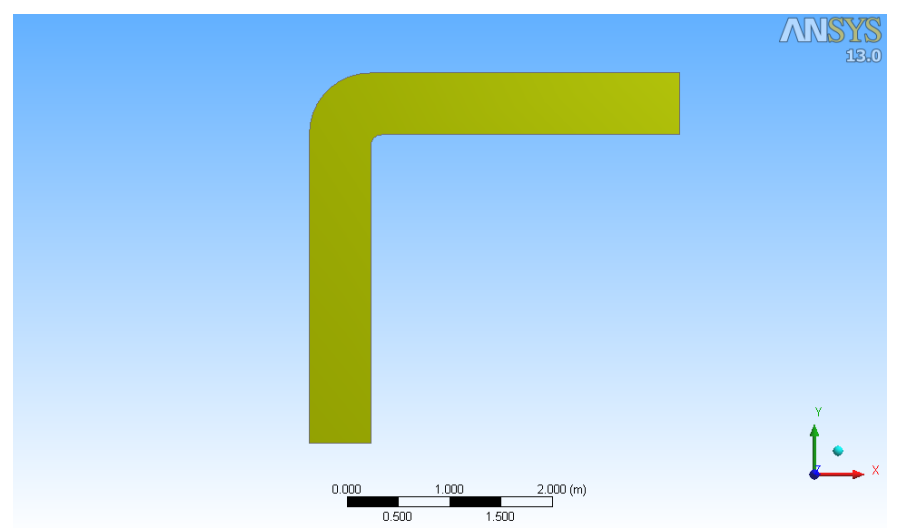

Fig. 4 Geometry representation

After the creation of the geometry we have discretised the body into 4159 discretisation cells with 8836 nodes (Fig. 5). A special attention was given to the part were the pipe bends, consisting in a larger number of cells, because here the air and the wheat changes direction and forms eddies.

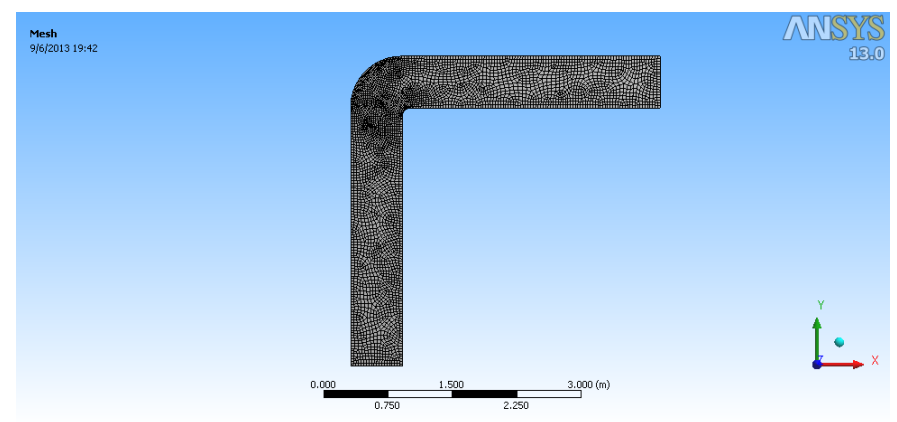

Fig. 5 Body discretisation

On one side of the pipe enters the air and wheat with a volume fraction of $50 \%$ each with a speed of $15 \mathrm{~m} / \mathrm{s}$. The two phases will mix and will reach the other side at atmospheric pressure of $101,325 \mathrm{~Pa}$. The density of the air was equal to $1.225 \mathrm{~kg} / \mathrm{m}^{3}$ and the wheat density was $800 \mathrm{~kg} / \mathrm{m}^{3}$. The pipeline is on horizontal plane so no gravity is used.

To calculate the two-phase transportation (air and wheat) we have used the volume fraction method. The volume fraction method relies on the fact that two or more fluids are not interpenetrating. For each additional phase that is added to the model, a variable is introduced: the volume fraction of the phase in the computational cell. In each control volume, the volume fraction of all phases sum to unity. Thus, the variables and properties in any given cell are either purely representative of one of the phases, or representative of a mixture of the phases, depending upon the volume fraction values [5].

$$
\frac{1}{\rho_{q}}\left[\frac{\partial}{\partial t}\left(\alpha_{q} \rho_{q}\right)+\nabla \cdot\left(\alpha_{q} \rho_{q}\right)=S_{\alpha_{q}}+\sum_{p=1}^{n}\left(\dot{m_{p q}}-\dot{m}_{p q}\right)\right]
$$

where: $\dot{m}_{q p}$ is the mass transfer from phase $\mathrm{q}$ to phase $\mathrm{p}$ and $\dot{m}_{p q}$ is the mass transfer from phase $\mathrm{p}$ to phase $\mathrm{q} ; \alpha_{q}$ is the volume fraction of the phase q and $S_{\alpha_{q}}$ is a specific constant.

For turbulent model k-epsilon: we used the equation for turbulent kinetic energy k (23), disipation epsilon (24) and the energy equation (25) [5]:

$$
\begin{aligned}
& \frac{\partial}{\partial t}\left(\rho_{m} k\right)+\nabla \cdot\left(\rho_{m} \bar{v}_{m} k\right)= \\
& \quad=\nabla \cdot\left(\frac{\mu_{t, m}}{\sigma_{k}} \nabla k\right)+G_{k, m}-\rho_{m} \varepsilon \\
& \frac{\partial}{\partial t}\left(\rho_{m} \varepsilon\right)+\nabla \cdot\left(\rho_{m} \bar{v}_{m} \varepsilon\right)= \\
& =\nabla \cdot\left(\frac{\mu_{t, m}}{\sigma_{\varepsilon}} \nabla \varepsilon\right)+\frac{\varepsilon}{k}\left(C_{l \varepsilon} G_{k, m}-C_{2 \varepsilon} \rho \varepsilon\right) \\
& \frac{\partial}{\partial t}(\rho E)+\nabla \cdot(\bar{v}(\rho E+p))= \\
& =\nabla \cdot\left(k_{e f f} \nabla T-\Sigma_{j} h_{j} \bar{J}_{j}+\left(\bar{\tau}_{\text {eff }} \bar{v}\right)\right)+S_{h}
\end{aligned}
$$

where:

$$
\begin{gathered}
\rho_{m}=\sum_{i=1}^{N} \alpha_{i} \rho_{i}, \\
\bar{v}_{m}=\frac{\sum_{i=1}^{N} \alpha_{i} \rho_{i} \bar{v}_{i}}{\sum_{i=1}^{N} \alpha_{i} \rho_{i}}, \\
\mu_{t, m}=\rho_{m} C_{\mu} \frac{k^{2}}{\varepsilon}, \\
G_{k, m}=\mu_{t, m}\left(\nabla \bar{v}_{m}+\left(\nabla \bar{v}_{m}\right)^{T}\right): \nabla \bar{v}_{m}
\end{gathered}
$$

$\mathrm{k}_{\text {eff }}$ is effective conductivity; $\mathrm{J}_{\mathrm{j}}$ fluid diffusion flux $\mathrm{j} ; \mathrm{S}_{\mathrm{h}}$ heat due to chemical reaction. In the equation (25) we have:

$$
E=h-\frac{p}{\rho}+\frac{v^{2}}{2}
$$

$\mathrm{h}$ - enthalpy; for ideal fluids (9) and for real fluid (10)

$$
\begin{aligned}
& h=\Sigma_{j} Y_{j} h_{j} \\
& h=\Sigma_{j} Y_{j} h_{j}+\frac{p}{\rho}
\end{aligned}
$$




$$
h_{j}=\int_{T_{\text {ref }}}^{T} c_{p, j} d T
$$

The velocity variation shows us a increase of the velocity mixture from $15 \mathrm{~m} / \mathrm{s}$ to $17 \mathrm{~m} / \mathrm{s}$ when the mixture changes direction.
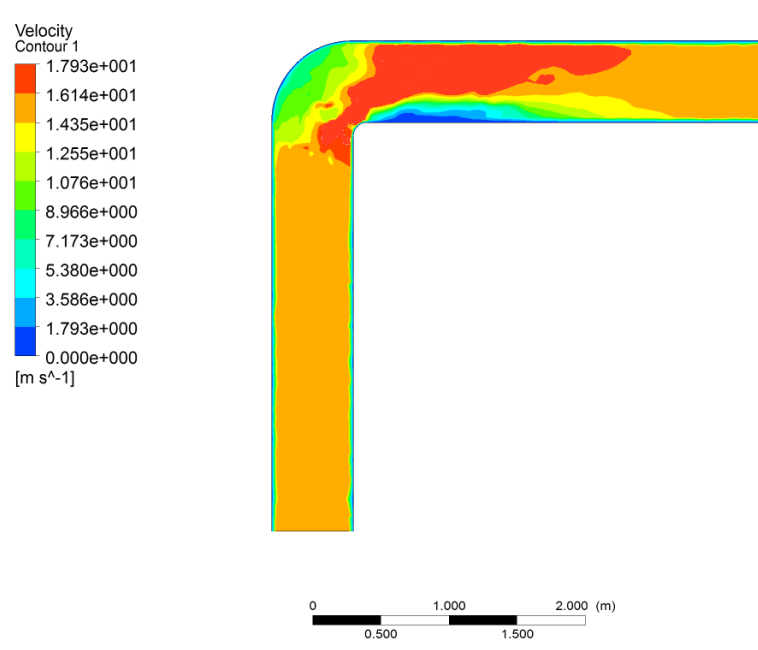

aNisYYS

Fig. 6 Velocity variation

The density representation shows actually the volume fraction distribution of phases (Fig. 7). The blue color is associated with air density, while the red color is associated with wheat density. The green color shows that in that specific region the computer averaged the density values that was depending on volume fraction of the phases.
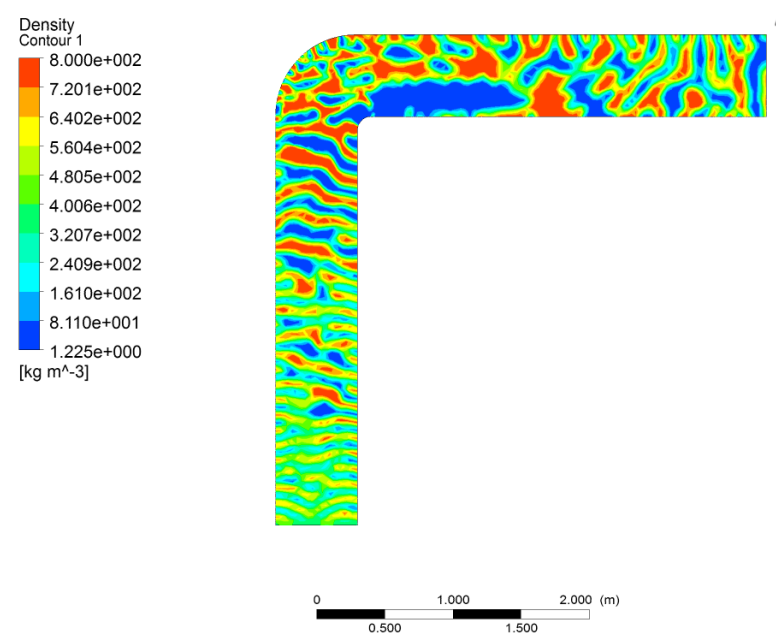

ANSTIS

Fig. 6 Density variation

\section{CALCULATION FOR PNEUMATIC GRAIN TRANSPORT SYSTEM}

\section{A) INITIAL DATA}

$\mathrm{v}_{\mathrm{a}}:=14$ air velocity $[\mathrm{m} / \mathrm{s}]$;

$\mathrm{d}:=2 \cdot 10^{-3} \div 6 \cdot 10^{-3}$ diameter of particle $[\mathrm{m}]$;

$\mathrm{Q}=250 \div 350[\mathrm{t} / \mathrm{h}]$-air flow of system.

B) RESULTS
1. Necessary diameter of the pipe conduct

$$
d_{i}=0,6 \sqrt{\frac{Q}{\mu v_{a} \gamma_{a}}}
$$

$\mathrm{Q}=250 \div 350[\mathrm{t} / \mathrm{h}]$-air flow of system;

$\gamma_{\mathrm{a}}=1,2\left[\mathrm{~kg} / \mathrm{m}^{3}\right]$ air density;

$\mu=15$ - concentration of mixture, for systems with grain suction;

Table 1. Calculation of necessary diameter to transport the grains for a certain air velocity

\begin{tabular}{|l|r|r|r|r|l|}
\hline $\begin{array}{l}\text { Nr. } \\
\text { Crt. }\end{array}$ & $\begin{array}{l}\mathbf{Q} \\
{[\mathbf{t} / \mathbf{h}]}\end{array}$ & $\boldsymbol{\mu}$ & \multicolumn{1}{|l|}{$\begin{array}{l}\mathbf{V}_{\mathbf{a}} \\
{[\mathbf{m} / \mathbf{s}]}\end{array}$} & $\begin{array}{l}\mathbf{g}_{\mathbf{a}} \\
{\left[\mathbf{k g} / \mathbf{m}^{3}\right]}\end{array}$ & $\begin{array}{l}\mathbf{d}_{\mathbf{i}} \\
{[\mathbf{m}]}\end{array}$ \\
\hline 1 & 250 & 15 & 14 & 1.2 & 0.597614 \\
\hline 2 & 260 & 15 & 14 & 1.2 & 0.609449 \\
\hline 3 & 270 & 15 & 14 & 1.2 & 0.621059 \\
\hline 4 & 280 & 15 & 14 & 1.2 & 0.632456 \\
\hline 5 & 290 & 15 & 14 & 1.2 & 0.64365 \\
\hline 6 & 300 & 15 & 14 & 1.2 & 0.654654 \\
\hline 7 & 310 & 15 & 14 & 1.2 & 0.665475 \\
\hline 8 & 320 & 15 & 14 & 1.2 & 0.676123 \\
\hline 9 & 330 & 15 & 14 & 1.2 & 0.686607 \\
\hline 10 & 340 & 15 & 14 & 1.2 & 0.696932 \\
\hline 11 & 350 & 15 & 14 & 1.2 & 0.707107 \\
\hline
\end{tabular}

\section{Transport velocity}

$$
v_{p}=k \sqrt{\frac{28,4 d^{\prime} \gamma_{m}}{\gamma_{a}}}
$$

Where, $\mathrm{d}^{\prime}=4 \cdot 10^{-3}[\mathrm{~m}]$ - diameter of particle; $\mathrm{k}=0,57$ - shape coefficient; $\gamma_{\mathrm{a}}=1,2\left[\mathrm{~kg} / \mathrm{m}^{3}\right]$ air density; $\gamma_{\mathrm{m}}=7000 \div 8500\left[\mathrm{~N} / \mathrm{m}^{3}\right]$-specific weight of grain.

Table 2. Calculation of transport velocities for different specific weights

\begin{tabular}{|c|c|c|c|c|}
\hline $\mathbf{N r}$. & $\begin{array}{c}\mathbf{g}_{\mathbf{m}} \\
{\left[\mathbf{N} / \mathbf{m}^{3}\right]}\end{array}$ & $\begin{array}{c}\mathbf{d} \mathbf{}^{\mathbf{m}} \\
{[\mathbf{m}]}\end{array}$ & $\begin{array}{c}\mathbf{g}_{\mathbf{a}} \\
{\left[\mathbf{k g} / \mathbf{m}^{3}\right]}\end{array}$ & $\begin{array}{c}\mathbf{V}_{\mathbf{p}} \\
{[\mathbf{m} / \mathbf{s}]}\end{array}$ \\
\hline 1 & 7000 & 0.004 & 1.2 & 14.67312 \\
\hline 2 & 7100 & 0.004 & 1.2 & 14.77755 \\
\hline 3 & 7200 & 0.004 & 1.2 & 14.88126 \\
\hline 4 & 7300 & 0.004 & 1.2 & 14.98424 \\
\hline 5 & 7400 & 0.004 & 1.2 & 15.08653 \\
\hline 6 & 7500 & 0.004 & 1.2 & 15.18812 \\
\hline 7 & 7600 & 0.004 & 1.2 & 15.28904 \\
\hline 8 & 7700 & 0.004 & 1.2 & 15.3893 \\
\hline 9 & 7800 & 0.004 & 1.2 & 15.4889 \\
\hline 10 & 7900 & 0.004 & 1.2 & 15.58788 \\
\hline 11 & 8000 & 0.004 & 1.2 & 15.68622 \\
\hline 12 & 8100 & 0.004 & 1.2 & 15.78396 \\
\hline 13 & 8200 & 0.004 & 1.2 & 15.88109 \\
\hline 14 & 8300 & 0.004 & 1.2 & 15.97763 \\
\hline 15 & 8400 & 0.004 & 1.2 & 16.0736 \\
\hline 16 & 8500 & 0.004 & 1.2 & 16.16899 \\
\hline
\end{tabular}

3. Necessary air flow to transport the grains $-\mathrm{Q}_{\mathrm{a}}$

$$
Q_{a}=\frac{Q}{4,3 \mu}
$$

$\mathrm{Q}=250 \div 350[\mathrm{t} / \mathrm{h}]$-air flow of system 
$\mu=15$ - concentration of mixture, for systems with grain suction;

Table 3. Calculation of necessary air flow to transport the grains for different air flows of the system

\begin{tabular}{|l|r|r|r|}
\hline Nr. & $\begin{array}{l}\text { Q } \\
{[\mathbf{t} / \mathbf{h}]}\end{array}$ & \multicolumn{1}{|l|}{$\boldsymbol{\mu}$} & $\begin{array}{l}\mathbf{Q}_{\mathbf{a}} \\
{[\mathbf{t} / \mathbf{h}]}\end{array}$ \\
\hline 1 & 250 & 15 & 3.875969 \\
\hline 2 & 260 & 15 & 4.031008 \\
\hline 3 & 270 & 15 & 4.186047 \\
\hline 4 & 280 & 15 & 4.341085 \\
\hline 5 & 290 & 15 & 4.496124 \\
\hline 6 & 300 & 15 & 4.651163 \\
\hline 7 & 310 & 15 & 4.806202 \\
\hline 8 & 320 & 15 & 4.96124 \\
\hline 9 & 330 & 15 & 5.116279 \\
\hline 10 & 340 & 15 & 5.271318 \\
\hline 11 & 350 & 15 & 5.426357 \\
\hline
\end{tabular}

4. Necessary power of pneumatic transport installation

$$
\begin{gathered}
P=\frac{k L}{10^{2} \eta}[\mathrm{kW}] \\
L=10000 Q_{a} \ln \frac{10000}{10000-h_{\text {tot }}}[\mathrm{daNm} / \mathrm{s}]
\end{gathered}
$$

$\mathrm{k}=1,1$ - coefficient that takes account of losses of leakage;

$\mathrm{h}_{\text {tot }}=$ pressure drop;

$\mathrm{Q}_{\mathrm{a}}=$ air mass flow;

$\eta=$ efficiency of the pump.

We have calculated the necessary power of pneumatic transport for all 11 cases of the necessary air flow, thus resulting 11 tables. That is way we have presented here all the first two tables and the lost one.

\begin{tabular}{|c|c|c|c|c|c|}
\hline Nr. & $\begin{array}{l}Q_{a} \\
{[t / h]}\end{array}$ & $\begin{array}{l}\mathbf{L} \\
{[\mathrm{Nm} / \mathrm{s}]}\end{array}$ & h & $\mathbf{k}$ & $\begin{array}{l}\mathbf{P} \\
{[\mathrm{kW}]}\end{array}$ \\
\hline 1 & 3.875969 & 514468.5 & 0.8 & 1.1 & 7.073942 \\
\hline 2 & 3.875969 & 514496.3 & 0.8 & 1.1 & 7.074324 \\
\hline 3 & 3.875969 & 514524 & 0.8 & 1.1 & 7.074705 \\
\hline 4 & 3.875969 & 514551.8 & 0.8 & 1.1 & 7.075087 \\
\hline 5 & 3.875969 & 514579.6 & 0.8 & 1.1 & 7.075469 \\
\hline 6 & 3.875969 & 514607.3 & 0.8 & 1.1 & 7.075851 \\
\hline
\end{tabular}

Table 4. Calculation of necessary power for $\mathrm{Q}_{\mathrm{a}}=3.875969[\mathrm{t} / \mathrm{h}]$

\begin{tabular}{|c|c|c|c|c|c|}
\hline Nr. & $\begin{array}{l}Q_{a} \\
{[t / h]}\end{array}$ & $\begin{array}{l}\mathbf{L} \\
{[\mathrm{Nm} / \mathrm{s}]}\end{array}$ & $\mathbf{h}$ & $\mathbf{k}$ & $\begin{array}{l}P \\
{[\mathrm{~kW}]}\end{array}$ \\
\hline 1 & 4.031008 & 535047.3 & 0.8 & 1.1 & 7.3569 \\
\hline 2 & 4.031008 & 535076.1 & 0.8 & 1.1 & 7.357297 \\
\hline 3 & 4.031008 & 535105 & 0.8 & 1.1 & 7.357694 \\
\hline 4 & 4.031008 & 535133.9 & 0.8 & 1.1 & 7.358091 \\
\hline 5 & 4.031008 & 535162.8 & 0.8 & 1.1 & 7.358488 \\
\hline 6 & 4.031008 & 535191.7 & 0.8 & 1.1 & 7.358885 \\
\hline
\end{tabular}

Table 5. Calculation of necessary power for $\mathrm{Q}_{\mathrm{a}}=4.031008[\mathrm{t} / \mathrm{h}]$

\begin{tabular}{|c|c|c|c|c|c|}
\hline Nr. & $\begin{array}{l}\mathbf{Q}_{\mathrm{a}} \\
{[\mathrm{t} / \mathbf{h}]}\end{array}$ & $\begin{array}{l}\mathrm{L} \\
{[\mathrm{Nm} / \mathrm{s}]}\end{array}$ & h & $\mathbf{k}$ & $\begin{array}{l}\text { P } \\
{[\mathrm{kW}]}\end{array}$ \\
\hline 1 & 5.426357 & 699677.2 & 0.8 & 1.1 & 9.90352 \\
\hline 2 & 5.426357 & 699714.9 & 0.8 & 1.1 & 9.904054 \\
\hline 3 & 5.426357 & 699752.7 & 0.8 & 1.1 & 9.904588 \\
\hline 4 & 5.426357 & 699790.4 & 0.8 & 1.1 & 9.905123 \\
\hline 5 & 5.426357 & 699828.2 & 0.8 & 1.1 & 9.905657 \\
\hline 6 & 5.426357 & 699866 & 0.8 & 1.1 & 9.906192 \\
\hline
\end{tabular}

Table 6. Calculation of necessary power for $\mathrm{Q}_{\mathrm{a}}=5.426357[\mathrm{t} / \mathrm{h}]$

\section{CONCLUSIONS}

We can observe that an increase of grain dimensions leads us an increase of velocity, for a certain specific weight. Also we can notice that the necessary power of the system increases with increasing air flow and the velocity of transported material implicitly. This shows that you have to make a compromise: what velocity of transport should be chosen (the bigger, the better) and what power or energy we have at hand. Varying these parameters we can optimize the transportation system.

\section{References}

[1] [1] O. Bancea," "Industrial ventilation" , Politehnica Publishing,Timisoara, 2009.

[2] [2]O.Bancea,"Ventilation and air condition", lecture notes, Politehnica Publishing,Timisoara, 1996.

[3] [3] W. BARTH,Absetzung, Transport und Fiedersufwirbelung von staubförmigem Gut im Luftstrom. Chemie Ing.Technic no.3/1963.

[4] [4] E.CARAFOLI, T.,OROVEANU, Fluids mechanics, Romanian Academy Publishing Bucharest,vol.I, pp.295-387,1952, vol.II, pp.489$552,1955$.

[5] Ansys-Fluent v.12 Theory guide, 2007.

\section{Creative Commons Attribution License 4.0 (Attribution 4.0 International, CC BY 4.0)}

This article is published under the terms of the Creative Commons Attribution License 4.0

https://creativecommons.org/licenses/by/4.0/deed.en US 